\title{
Jean Bérenger
}

\section{Die Habsburger und ihre Erbfolgekrisen als Formationsphase des neuen europäischen Staatensystems}

Das Haus Habsburg hat durch das Erlöschen im Mannesstamm zuerst in Spanien, dann in Österreich, innerhalb eines Jahrhunderts zwischen dem Pyrenäenfrieden (1659) und dem Aachener Frieden (1748) drei Erbfolgekrisen verursacht: Es waren dies der Spanische Erbfolgekrieg (1702-1714), der Österreichische Erbfolgekrieg (1740-1748) und zusätzlich der Polnische Erbfolgekrieg (1733-1738). Am Anfang des 18. Jahrhunderts erhob das Erzhaus noch Ansprüche auf die Universalmonarchie, und es wollte mindestens den status quo bewahren, d. h. die Spanische Monarchie ungeteilt erhalten und die seit dem Frieden von Karlowitz beträchtlich erweiterte Donaumonarchie, die Niederlande und Italien weiterhin regieren. Das beweist zum Beispiel die die Sukzession der Spanischen Monarchie betreffende Erklärung des Kaisers Leopold vor der Geheimen Konferenz am 12. September 1703 vor der Abfahrt Erzherzog Karls nach der Iberischen Halbinsel:

„Welche durch Absterben weyland Königs in Spanien Carl II. Krafft aller Rechten gemachter Verträgen und gethanen Verzichten dem Ertzhause Oesterreich wäre heimgefallen; Weil nun er der rechtmässige einzige Erbe aller solchen Spanischen Reiche wäre, diese aber zu regieren und mit seinen andern Erbländern zu vereinigen, er ein billiches Bedenken trüge: so hatte er zwar allergnädigist resolvirt gehabt, diese ganze Erbschafft dem Röm. König als primogenito zukommen zu lassen. Weil aber an Seiten hohbedachten Königs auch viel zu gedencken gewesen, als hatte er für ratsam befunden, diese seine ihm zukommende Erbschafft der Spanischen Monarchie seinem andern Sohn, dem Ertz-Herzog Carl, doch mit gewisser Condition und Reservation auf dic Manicr wie vormals seine Vorfahren des Ertz-hauses Oesterreich, Carolus V. und andere gethan, pleno jure $\&$ titulo zu credieren, und ihn also für einen rechtmässigen König aller Spanischen Reiche zu declariren. ${ }^{1}$

Nach dem Aachener Frieden herrschte Maria Theresia über die Donaumonarchie, die Niederlande und Mailand, obwohl die österreichische Vormachtstellung in Deutschland schon von Preußen bestritten wurde. Diese für die Habsburger peinliche Entwicklung war vor allem die dramatische Konsequenz einer biologischen Schwächung des Erzhauses: zuerst das Erlöschen der spanischen Linie im November 1700 nach dem Tod König Karls II. und 40 Jahre später das Erlöschen

1 Wien, 12. September 1703. Zitiert in Gottlieb Eucharius Rinck, Leopolds des Grossen Leben und Thaten, Bd. 2 (Leipzig 1708) 1035-1036. 
des Erzhauses in männlicher Linie nach dem Tode Kaiser Karls VI. Das war übrigens kein reiner Zufall, und die Habsburger waren teilweise dafür verantwortlich, weil die seit 1550 wiederholten Eheschließungen zwischen nahen Verwandten beider Linien, die theoretisch zum Schutz der Erbschaft gegen Ansprüche fremder Häuser geschlossen worden waren, zu einer endgültigen Katastrophe geführt hatten. Zwar hat jedes königliche Haus Heirat zwischen Vettern und Kusinen praktiziert (Bourbonen und Stuart, Bourbonen und Habsburger), bei den Habsburgern jedoch wurde die Endogamie übertrieben, weil der Onkel auch seine Nichte heiratete. Indessen konnten die Habsburger sich nicht für die Exogamie entscheiden, weil sie an dem Prinzip der Einheit des Erzhauses festhielten. Schon Philipp III. von Spanien hat auf seine Rechte an der Hinterlassenschaft von Kaiser Matthias nur verzichtet, weil ihm damals eine für die Madrider Strategie wichtige Kompensation, das Oberelsaß, versprochen wurde ${ }^{2}$. Und nach dem Tode Philipps IV. überlebte während 20 Jahren nur ein gesunder männlicher Sprößling, Kaiser Leopold I., der vor 1678 nicht imstande war, einen lebensfähigen Sohn zu bekommen. Dank seiner Vermählung in dritter Ehe mit einer "kräftigen“ Prinzessin, Eleonora von Pfalz-Neuburg ${ }^{3}$, hat Kaiser Leopold für eine gewisse Zeit die $\mathrm{Zu}-$ kunft seines Hauses gerettet. Die Geburt eines zweiten lebensfähigen Sohnes, des Erzherzogs Karl, im Jahre 1685 hat die Situation beträchtlich geändert: Der erstgeborene, zur Kaiserkrone bestimmte Erzherzog wurde schon 1686 zum Römischen König gewählt und bei der 1687er Sitzung des ungarischen Reichstags auch als ungarischer König gekrönt; der jüngere Prinz, der eine besondere Erziehung bekam, wurde für die Spanische Krone bestimmt. Diese Pläne waren in der Sicht des Erzhauses zwar vernünftig, sie berücksichtigten aber weder das spanische $\mathrm{Na}$ tionalgefühl noch den neuen Begriff des europäischen Gleichgewichts und vernachlässigten die Ansprüche der Bourbonen auf die spanische Erbschaft.

Trotz der früheren Entsagung der Infantin Anna auf die spanische Monarchie und trotz des wohlbekannten Verzichts der Infantin Maria Theresia anläßlich ihrer Vermählung, erhob Ludwig XIV. im Namen seiner Gattin und später seiner Kinder bald Ansprüche auf das spanische Erbe, was in der 2. Hälfte des 17. Jahrhunderts zu drei Teilungsverträgen führte, die in den Jahren 1668, 1699 und 1700 geschlossen wurden. Im ersten Fall wurde das Abkommen mit dem potentiellen Universalerben, Kaiser Leopold I., unterzeichnet, in den zwei letzten Fällen hat der Sonnenkönig mit seinem Feind Wilhelm III. ohne Zustimmung des Kaisers verhandelt. In allen drei Fällen wollte man aber zugleich die Interessen der Bour-

2 Onate-Vertrag (geheim) von 1617. Über die Wichtigkeit des Oberelsaß für die Verbindungen zwischen Mailand und den Niederlanden, siehe Geoffrey Parker, The Army of Flanders and the Spanish Road. The Logistics of Spanish Victory and Defeat, 1567-1659 (Cambridge 1972).

${ }^{3}$ Sie war die Tochter des späteren pfälzischen Kurfürsten, Georg Wilhelm, der 1685 Nachfolger seines kinderlosen Vetters Karl von der Pfalz wurde. Die Ansprüche Ludwigs XIV. im Namen seiner Schwägerin Liselotte auf die Allodialgüter waren eine der vielfältigen Ursachen des Pfälzischen Erbfolgekrieges. Siehe Charles Boutant, L'Europe au grand tournant des années 1680. La succession palatine (Paris 1985). 
bonen und den europäischen Frieden retten. Gegen die Überlassung einiger Territorien, auf welche die Krone Frankreichs besondere Ansprüche aufgrund historischer Rechte erhob (z. B. auf den Burgundischen Kreis und das Königreich Navarra), hat Ludwig XIV. im Jahre 1668 die Rechte des Erzhauses anerkannt. Diese Teilungsverträge beruhten aber auf anderen Grundsätzen, und zwar auf dem Fortbestehen des allgemeinen Friedens und des europäischen Gleichgewichtes sowie auf der verhältnismäßigen Schwäche der Donaumonarchie in militärischer und wirtschaftlicher Hinsicht. Diese im Jahre 1668 wohl begründete Analyse war im Jahre 1700 nach der Wiedereroberung Ungarns und dem Auftauchen der Seemächte als europäischen Machtfaktoren weniger berechtigt ${ }^{4}$.

Die Erbfolgekrisen der Habsburger trugen also zu einer Umwälzung des europäischen Staatensystems beträchtlich bei und störten manchmal erheblich den Frieden zwischen den europäischen Großmächten. Sie stellten einen bedeutenden Faktor des europäischen Staatensystems zur Zeit des Absolutismus dar. Das europäische Gleichgewicht ${ }^{5}$ wurde jederzeit durch Erbfolgeprobleme umgestaltet, weil die monarchischen Staaten noch am veralteten Charakter von Patrimonialstaaten festhalten wollten. Und das dynastische Europa blieb gegen den Willen seiner Herrscher eine Quelle unzähliger Konflikte infolge des Aussterbens herrschender Häuser und der durch die Nebenlinien aufgrund von Erbrechten erhobenen Ansprüche. Insbesondere sechs Erbfolgeprobleme haben in der 1. Hälfte des 18. Jahrhunderts den europäischen Regierungen große Sorgen gemacht. Von ihnen haben drei zu einer bedeutenden Krise geführt.

Der Spanische Erbfolgekrieg veränderte das europäische Gleichgewicht grundlegend. Sein Ursprung liegt in der biologischen Schwäche der Hauptlinie, d. h. der spanischen Linie des Hauses Habsburg. Das Problem wurde schon während der Friedensverhandlungen in Münster von den spanischen und französischen Delegationen erwähnt. Nach dem frühen Tod des Infanten Don Balthazar Carlos, eines begabten Jungen, schlug Kardinal Mazarin schon im Jahre 1646 König Philipp IV. die Heirat der Infantin Maria Theresia mit ihrem Vetter Ludwig XIV. vor; der Bruch der Verhandlungen zwischen beiden Kronen in Münster verschob die Verwirklichung dieses Heiratsplanes bis zum Pyrenäenfrieden. Jeder vernünftige Staatsmann wußte in Paris ebenso wie in Madrid oder in Wien, daß der formelle Verzicht der jungen Königin von Frankreich nicht ernst genommen werden sollte und daß Frankreich in Zukunft einmal Ansprüche auf die spanische Erbschaft erheben werde. Nach der Geburt des Infanten Don Carlos, des krankhaften Sprößlings aus der zweiten Ehe König Philipps IV. mit seiner Nichte, der Erzherzogin Maria Anna, entspannte sich dic Situation vorübergehend. Kaiser Leopold erkannte sehr früh, daß cr alleine nicht imstande war, die „These des Erzhauses“ zu

${ }^{4}$ Jean Bérenger, Finances \& absolutisme autrichien dans la seconde moitié du XVIIème siècle (Paris 1975).

5 Es entspricht dem englischen Begriff „Balance of Power“, die nach der Glorreichen Revolution den Grundsatz der britischen Diplomatie bis zum ersten Weltkrieg darstellte. Siche auch die Diskussion in Georges Livet, L'équilibre européen de la fin du XV à la fin du XVIII siècle (Paris 1976) 186-225. 
vertreten und als Universalerbe das Reich Karls V. zugunsten der deutschen Linie des Hauses Habsburg wiederherzustellen. Das europäische Staatensystem hatte sich seit der Zeit der frühen Reformation beträchtlich gewandelt, und die Seemächte sowie die Reichsstände hätten nicht erlaubt, daß das europäische Festland von der habsburgischen Universalmonarchie beherrscht würde. Deswegen versuchte Kaiser Leopold I. schon im Januar 1668 mit einem geheimen Teilungsvertrag, dem sogenannten Grémonville-Vertrag, mit Hilfe Frankreichs den größten Teil seiner Erbschaft zu retten ${ }^{6}$. Diese Annäherung an Frankreich während des Krieges Ludwigs XIV. gegen die spanische Monarchie in den Niederlanden war eine Folge der damaligen militärischen und wirtschaftlichen Schwäche Österreichs. Wenn auch ein Teil der geheimen Konferenz, die sogenannte spanische Partei unter der Leitung von Montecuccoli, bereit war, Spanien in den Niederlanden militärisch zu unterstützen und Hilfstruppen dem Statthalter Marqués de Castel-Rodrigo zur Verfügung zu stellen, war sich jedoch die Mehrheit der kaiserlichen Regierung unter der Leitung des Fürsten Wenzel von Lobkowitz vollkommen der Gefahr bewußt, die im Fall eines erneuten Krieges mit Frankreich der Monarchie gedroht hätte. Deswegen antwortete Fürst Lobkowitz auf den Vorschlag des französischen Staatsministers Hugues de Lionne positiv und verhandelte im Winter am Kaiserhof mit dem französischen Residenten am Kaiserhofe, dem Malteserritter Grémonville, über einen Ausgleich, der schnell zum Ende des Devolutionskrieges führte. In dem Teilungsvertrag vom 19. Januar 1668 wurde über Teile des spanischen Gesamterbes wie folgt verfügt: Kaiser Leopold sollte nach dem Tod seines Schwagers, Karls II., Spanien, Lateinamerika, Mailand, Sardinien und die toskanischen Praesidios bekommen, während der burgundische Kreis (Spanische Niederlande und Freigrafschaft), die Königreiche Navarra (als 1512 verlorener Patrimonialstaat der Bourbonen), Neapel und Sizilien sowie die afrikanischen Praesidios und die Philippinen an Ludwig XIV. gehen sollten?.

Das unerwartete Weiterleben des jungen Königs von Spanien verschob dreißig Jahre lang die Krise. Als sich am Ende des Pfälzischen Erbfolgekrieges die Ge-

${ }^{6}$ Jean Bérenger, An Attempted Rapprochment Between France and the Emperor, in: Ragnhild Hatton (Hrsg.), Louis XIV and Europe (London 1976) 133-152.

7 "Qu'il échoie et tombe en partage à Sa Majesté Impériale \& à ses enfants pour leur portion d'héritage, les royaumes d'Espagne, excepté les réserves dont il sera fait mention ci-dessous, les Indes occidentales, le duché de milan, avec le droit qui en dépend de donner l'investiture au duché de sienne. Finale les ports nommés Longone, Ercole, Orbetello et les autres ports qui sont soumis à la couronne d'Espagne sur les côtes de la mer de Toscane, jusqu'aux frontières du royaume de Naples, avec leurs dépendances, l'île de Sardaigne, les Canaries et les îles Baléares, appelées vulgairement Majorque, Minorque \& Ibiza. Et qu'il tombe et appartienne à Sa Majesté Très Chrétienne et à ses héritiers pour leur part d'héritage tout ce que les Espagnols possèdent dans les Pays-Bas, sous quoi l'on comprend aussi la Bourgogne, dite la Franche-Compté, les îles Philippines, le royaume de Navarre avec ses dépendances; les lieux situés sur les côtes d'Afrique, les royaumes de Naples et de Sicile avec leurs dépendances et les lieux qui en dépendent aujourd'hui sans néanmoins comprendre les ports appelés Longone, Ercole, Orbetello [...]. “ Artikel Nr. 3 des Teilungsvertrags vom 9. Januar 1668. Das lateinische Original mit eigenhändiger Ratifikation Ludwigs XIV. in: Wien, Haus-, Hof- und Staatsarchiv, Staatskanzlei, Verträge. 
sundheit König Karls II. beträchtlich verschlechterte, war die politische Gesamtlage Europas eine andere, so daß Kaiser Leopold nichts mehr von einer Teilung der spanischen Monarchie hören wollte und an der Theorie von der Einigkeit des Hauses Habsburg festhielt, auf welche er doch im ersten Teilungsvertrag verzichtet hatte. Gemäß dieser Konzeption bestand das Erzhaus aus zwei oder mehreren Linien, die den Patrimonialstaat Kaiser Karls V. regierten, so daß das Aussterben einer männlichen Linie die andere Linie zum Universalerben des Gesamtstaats machte. Die mit fremden Fürsten verheirateten Töchter sollten automatisch nach ihrem formellen Verzicht von der Erbschaft ausgeschlossen sein.

Nach dem Frieden von Rijswijck wurde die spanische Erbfolge wieder aktuell, weil es damals klar war, daß Karl II. nach zwei Heiraten ${ }^{8}$ endgültig kinderlos bleiben und die spanische Linie des Hauses Habsburg bald aussterben werde. Die Großmächte waren aber uneins, was die Lösung des unmittelbar bevorstehenden Problems betraf: Einerseits hielt Kaiser Leopold an seiner Interpretation der „Hausordnung" wieder einmal fest, da er jetzt zwei erwachsene Söhne hatte und $\mathrm{da}$ der Jüngere für die spanische Krone bestimmt wurde. Andererseits befürchteten die Seemächte und vor allem Wilhelm von Oranien, als nach einem kostspieligen Kampf der allgemeine Friede wiederhergestellt war, einen wenig nützlichen Krieg in Europa für den Fall, daß Frankreich seine Ansprüche auf die Erbschaft der Königin Maria Theresia erheben würde. Deshalb war der König von England und "Stadhouder" der Vereinigten Provinzen bereit, über einen Ausgleich mit Ludwig XIV. zu verhandeln, damit der allgemeine Frieden erhalten werden könne.

Nach der Ratifikation des Rijswijcker Friedens erteilte Ludwig seinem Botschafter in London, Graf von Tallard, vernünftige Weisungen ${ }^{9}$, da er wohl wußte, daß die Engländer nicht bereit waren, einen Krieg im alleinigen Interesse des Kaisers zu führen. Im schließlich zustande gekommenen Teilungsvertrag wurde dem Geist des neuen Staatensystems gemäß eine Kompromißlösung gefunden: Der bayerische Kronprinz Ferdinand als einziger Sohn der Infantin Margareta, der Ansprüche auf das spanische Erbe erheben konnte, sollte zum Universalerben der Krone Spaniens erklärt werden, während Frankreich und der Kaiser ein bescheidenes Entgelt bekommen sollten. Die Königreiche Sizilien, Sardinien und Neapel wurden den Bourbonen, das Herzogtum Mailand dem Erzherzog Karl zugesprochen. Praktisch hätte Prinz Ferdinand nur Spanien, die Niederlande und Lateinamerika bekommen. Die Sicherheit der Vereinigten Provinzen und Englands wäre aber insofern gewährleistet gewesen, als Frankreich daran gehindert wurde, die spanischen Niederlande zu annektieren und die Nordseeküste zu besetzen. Diese Kombination fand wenig Zustimmung - weder in Wien noch in Madrid. Der

${ }^{8}$ Er heiratete zuerst 1679 eine Nichte Ludwigs XIV., die Prinzessin Marie-Louise d'Orléans, und, nach ihrem Tod, 1689 eine Schwester der Kaiserin Eleonora, Maria Anna von PfalzNeuburg.

9 Recueil des Instructions aux Ambassadeurs \& ministres de France depuis les Traités de Westphalie jusqu'à la révolution (weiter Instructions aux Ambassadeurs), Bd. XXV., Angleterre, hrsg. von Paul Vaucher (Paris 1954) 4-9. 
frühzeitige Tod des bayerischen Kronprinzen zu Beginn des Jahres 1699 zwang die Kabinette von London und Versailles, eine neue Lösung zu finden, was zu einem dritten Teilungsvertrag über die spanische Erbschaft führte, der überhaupt keine Genehmigung durch die Spanier und den Kaiser fand. Diesmal sollten die Bourbonen andere italienische Länder bekommen, und zwar Mailand und Sardinien. Durch deren Tausch mit Savoyen und Lothringen hätte Frankreich seine strategischen Grenzen noch weiter gesichert und die lothringische Frage endgültig gelöst. Solch ein Vorschlag hatte jedoch den Nachteil, den Nationalstolz der Spanier und die Eigensinnigkeit der Habsburger zu verletzen, wenn auch dem Erzherzog Karl die Möglichkeit blieb, in Madrid zu herrschen. Darum veranlaßte die spanische Nationalpartei in Madrid unter Leitung Kardinal Portocarreros, den kränkelnden König nach Absprache mit Papst Innozenz XII. ein Testament zugunsten eines Enkels von Königin Maria Theresia zu schreiben, das eine doppelte Bedingung enthielt: Die spanische Monarchie dürfe nie geteilt und mit dem französischen Königreich niemals vereinigt werden. Für den Fall, daß dieses Testament von Frankreich nicht angenommen würde, sollte Erzherzog Karl zum Universalerben erklärt werden. Eine Kompensation für die Bourbonen war für diesen Fall nicht vorgesehen. Auf diese Weise sollte die Integrität der spanischen Monarchie gerettet und der kastilische Nationalstolz befriedigt werden. Es ist bemerkenswert, daß ein Habsburger das Nationalgefühl seiner Untertanen bevorzugte und das reine Interesse seines Hauses vernachlässigte, weil er sich bewußt war, daß die damals geschwächte spanische Monarchie und die zur Großmacht werdende österreichische Monarchie ${ }^{10}$ nicht imstande waren, einen Krieg gegen Frankreich und die Seemächte zu gewinnen. Am 2. Oktober 1700 wurde nach langen Verhandlungen das verhängnisvolle Testament vom todkranken König Karl II. endlich unterzeichnet, der einen Monat später starb. Schon an 16. November 1700, nach zwei dramatischen Sitzungen des königlichen Rats, nahm Ludwig XIV. im Namen seines Enkels Philipp, Herzog von Anjou, das Testament des verstorbenen Königs von Spanien an. Die Annahme dieses Testaments wurde jedoch im königlichen Rat ("Conseil d'En haut") heftig diskutiert. In den Diskussionen standen sich zwei Positionen gegenüber ${ }^{11}$. Die eine, die im Rat vom Staatssekretär Colbert de Torcy ${ }^{12}$ und vom Staatsminister Herzog von Beauvillier ${ }^{13}$ vertreten

10 Jean Bérenger, Le redressement économique autrichien sous le règne de Léopold 1er (1657-1705), in: Etudes danubiennes, I/1 (Straßburg 1985) 1-24.

11 Saint-Simon, Mémoires pour l'année 1700, hrsg. v. Gonzague Truc, Bd. 1 (Paris 1952) 788800. Der Herzog von Saint-Simon, der die Papiere von Colbert de Torcy zur Verfügung hatte, bietet uns ausnahmsweise eine detaillierte Darstellung von den beiden im Schloß Fontainebleau am 13. und 15. November 1700 gehaltenen Ratssitzungen.

12 Charles Colbert de Torcy war der älteste Sohn des ehemaligen Staatssekretärs Charles Colbert de Croissy, dessen Nachfolger er schon 1696 mit 20 Jahren geworden war. Bald zum Staatsminister, d. h. Mitglicd des königlichen Rats, befördert, war er der leitende Minister des Auswärtigen Amtes bis zum Tod Ludwigs XIV., der seine Tüchtigkeit hoch schätzte. Torcy war also ein Neffe des häufig "Grand Colbert" genannten Jean-Baptiste Colbert.

13 Der Herzog von Beauvillier war der Ajo des Herzogs von Bourgogne, des Enkels Ludwigs XIV., und cin Schwiegersohn des "Grand Colbert“. Obwohl er keine leitende Persön- 
wurde, kann im Hinblick auf die Befestigung des Territorialstaats als modern gewertet werden: Frankreich solle am Teilungsvertrag des Frühjahrs 1700 festhalten, Erzherzog Karl als spanischen König anerkennen. Es werde sein Entgelt (Mailand bzw. Lothringen) bekommen und sich vor allem einen blutigen Krieg ersparen. Weil man das lothringische Problem sofort durch den Austausch Lothringens gegen Mailand hätte lösen können, wurde dieser Standpunkt später von manchen französischen Historikern positiv bewertet ${ }^{14}$, die den Spanischen Erbfolgekrieg als unnötig und schädlich betrachteten. Die andere Position, die vom Staatskanzler Pontchartrain ${ }^{15}$ und vom "Grand dauphin" ${ }^{16}$ vertreten wurde, sah eine vollständige Änderung der französischen Haltung, den Verzicht auf jegliche Entschädigung für das Königreich und die Installation eines Sprößlings der Bourbonen auf dem spanischen Thron vor. Ihre Verfechter betonten, daß die auf diese Weise zu erzielenden Ergebnisse für Frankreich ebenso positiv sein würden: die „Erbfeindschaft" $z$ wischen beiden Nationen beseitigt und der amerikanische Markt für die französischen Kaufleute geöffnet, die bis jetzt nur über Sevilla durch Vermittlung der „Casa de Contrataciòn“ ihre Textilwaren nach Lateinamerika exportieren durften. In strategischer und wirtschaftlicher Hinsicht war diese Lösung für Frankreich viel interessanter als die erste, zumal das neutralisierte Lothringen des Herzogs Leopold für die Sicherheit des Königreiches keine Gefahr mehr darstellte. Die Gefahr eines Krieges war genauso groß, denn die Seemächte hätten nie für französische Interessen gekämpft, um Ludwig XIV. die aus dem Teilungsvertrag zustehenden Entschädigungen zu verschaffen. Sicher ist, daß die Realisierung jeder der beiden Alternativen zu einem Krieg mit Kaiser Leopold geführt hätte. Im ersten Fall wäre Spanien nur ein zusätzlicher Feind Frankreichs gewesen, im anderen konnte man auf die Unterstützung des kastilischen Reichs rechnen, dessen Eliten für einen Bourbonen als Gesamterben eintraten, zumal dieser allein aufgrund der Unterstützung durch Frankreich fähig war, die spanische Monarchie aus einer Katastrophe zu retten und ihre Einheit zu erhalten. Die Annahme des Testaments war also keine rein dynastische Lösung im Sinne des Familienehrgeizes des alternden Sonnenkönigs, wie es oft von Lavisse und seinen Schülern dargestellt wurde. Im Gegenteil - die Ankunft der Bourbonen in Madrid hatte mehr Vorteile für den Staat und die Nation. Mit der Realisierung dieser Konzeption ver-

lichkeit war, wurde er trotzdem vom Sonnenkönig zum Staatsminister ernannt. Über den königlichen Rat, siehe Roland Mousnier (Hrsg.), Le Conseil du roi, de Louis XII à la Révolution (Paris 1970).

14 Ernest Lavisse, Louis XIV, 2 Bde. (Neue Auflage, Paris 1979).

15 Louis Phélypeaux de Pontchartrain gehörte zu einer der berühmtesten Familien von Magistraten und Ministern des Ancien Régime. Zuerst Präsident des Parlaments der Bretagne in Rennes, stieg er 1689 zum Generalkontrolleur (Finanzminister) und Staatsminister und 1699 zum Staatskanzler, zur ansehnlichsten Würde der französischen Monarchie, auf.

${ }_{16}$ Der „Grand dauphin“ (1661-1711) war der einzige überlebende Sohn Ludwigs XIV. und Maria Theresias; er war der Vater des Herzogs von Anjou, des zukünftigen Philipp V. Früh gestorben im Jahre 1711, herrschte er nie über Frankreich, hatte aber seit einigen Jahren Sitz und Stimme im königlichen Rat („Conseil d'En haut“). 
lor das Haus Habsburg für immer seine Rechte auf einen wichtigen Teil seines Erbes und seine Stellung als mächtigste Dynastie in Europa.

Zunächst schickte Ludwig XIV. Tallard nach London zurück, um die britische Regierung zu beruhigen, die am Anfang nicht bereit war, Geld und Blut nur im Interesse der Habsburger aufzuopfern ${ }^{17}$. Noch im Sommer 1701 konnte man mit einem begrenzten Krieg mit dem Kaiser rechnen. Mehrere Fehler von französischer Seite kompromittierten jedoch die Durchführung des Planes. Der schicksalhafte Schlag, den das Testament Karls II. von Spanien für die Interessen des Hauses Habsburg darstellte, war aber zu schwer, um keine Reaktion der enterbten deutschen Linie zu provozieren. Kaiser Leopold, der seinen jüngeren Sohn für den spanischen Thron bestimmt hatte, weigerte sich, den neuen Herrscher Spaniens anzuerkennen. Schon im Frühjahr 1701 griff Prinz Eugen die bourbonischen Truppen in Mailand an, die von seinem schnellen Marsch über die Alpen überrascht wurden. Erst ein Jahr später erklärte Leopold I. dem König von Frankreich und dem Herzog von Anjou den Krieg, nachdem er die Unterstützung der Seemächte gefunden hatte ${ }^{18}$.

Zu diesem Zeitpunkt war aber die Situation für die Bourbonen nicht so verzwcifelt, denn der junge König Philipp V. wurde von den verschiedenen Ländern der spanischen Monarchie sowie von der kastilischen Nation und vom Heiligen Stuhl mit Begeisterung anerkannt: Die Statthalter der Niederlande (Kurfürst Max Emanuel von Bayern) und von Mailand (der Prinz von Vaudémont, ein unchelicher Sohn Herzog Karls IV. von Lothringen) haben dem jungen Herrscher sofort die Huldigung geleistet.

Ludwig XIV. beging zwei Fehler, die eine Herausforderung für die Seemächte waren; erstens ließ er die Festungen der niederländischen Barriere von französischen Soldaten besetzen; zweitens erkannte er den alten Prätendenten Jakob Stuart sofort nach dem Tod seines Vaters, des in Saint-Germain lebenden englischen Königs, als legitimen König von Großbritannien an. Die große Haager Allianz bildete im Oktober 1701 eine gegen die Bourbonen gerichtete Koalition, die nur eine totale Trennung zwischen Frankreich und Spanien und bescheidene Kompensationen für die Habsburger verlangte. Aber auch diese Forderung lief auf eine Teilung der spanischen Monarchie hinaus und bedeutete damit cine Verletzung des spanischen Nationalgefühls.

17 Instruktionen Ludwigs XIV. an Marschall de Tallard, Versailles, den 7. Dezember 1700, in: Instructions aux Ambassadeurs, Bd. XXV, Angleterre, 60-65.

${ }_{18}$ Die Motive Leopolds werden in der Kriegserklärung klar formuliert: „Comme incontinent après le décès de Charles II., Roi d'Espagne, \& Archiduc d'Autriche, sous prétexte d'un Testament que l'on suppose que ce Prince aurait fait, mais qui, en effet, est nul $\&$ de nulle valeur, \& que nonobstant tous les Contrats de mariage, Renonciations, Cessions, Traitez de Paix, \& Serments précédents, le Roi de France s'est emparé de tous les Roiaumes \& Terres de sadite Sérénité entre lesquelles il y en a aussi qui ont appartenu à nôtre Maison Archiducale, avant qu'elles fussent venues au pouvoir de la Couronne d'Espagne, outre celles qui relèvent de l'Empire; qu'il y a intrus son Petit-Fils le duc d'Anjou, \& a pris par force. "Déclaration de guerre de l'Empereur Léopold Ier à la France et au duc d'Anjou, Wien, den 15. Mai 1702, in: Du Mont, Corps Universel du droit des gens, Bd. VIII, 115-116. 
Der Krieg war lang und kostete beiderseits viele Opfer an Blut und Geld. Frankreich machte fast eine halbe Million Menschen mobil, sei es für das königliche Heer, für die Kriegsmarine oder für die Miliz. Man kämpfte in Übersee genauso heftig wie in Europa, obgleich Amerika als weniger wichtiger Kriegsschauplatz betrachtet wurde. Nach einer anfänglich glücklichen Phase wurden die Bourbonen im Gefolge der französischen Niederlage von Blenheim und der Aufgabe von Turin, was den Verlust von Bayern und Norditalien bedeutete, auf die Verteidigung zurückgeworfen. Im Jahre 1706 verkündete der Sieg von Prinz Eugen und Marlborough bei Ramillies den Beginn schwerer Zeiten für Frankreich, wenn auch die Belagerung von Toulon (1707) und der Verlust von Lille (1708) keine Erniedrigung bedeuteten.

Befördert von der englischen Kriegsmarine, konnte Erzherzog Karl 1704 in Portugal landen, um von dort aus die Eroberung seines neuen Königreichs mit Hilfe der Seemächte zu versuchen. Mit Ausnahme von Katalonien fand er in Spanien keine richtige Unterstützung. Nach 1707 residierte er in Barcelona. Als aber Ludwig XIV. nach dem leidlichen Feldzug des Jahres 1709 sich bereit erklärte, über einen Kompromißfrieden zu verhandeln, waren die Ansprüche der Alliierten so hoch und so wenig realistisch, daß die Verhandlungen von Gertruydenberg scheiterten: Ludwig XIV. lehnte es ab, seine Kräfte mit denen der Alliierten zu vereinigen, um seinen Enkel aus Spanien zu vertreiben. Es war schließlich das mit jeder dynastischen Politik verbundene Element des Zufalls, das der endgültigen Lösung einer Krise Bahn brach, die auf einer dynastischen Auseinandersetzung beruhte. Im Jahre 1711 starb der noch junge Kaiser Joseph I. unerwartet an den Blattern, so daß König Karl III. von Spanien, der in Barcelona unter dem Schutz der Seemächte seinen Rumpfstaat regierte, plötzlich der Alleinerbe des Habsburgerreichs wurde. Der frühverstorbene Kaiser Joseph hinterließ nur zwei minderjährige Töchter, und der Hausordnung des Jahres 1703 gemäß hatten sie kein Recht auf das habsburgische Erbe. Erst später, nach dem Tod ihres Onkels Karl, erlangten sie das Recht, Ansprüche auf die Erbschaft zu erheben. Diese hier nur angedeuteten Vorgänge führten zu einer entscheidenden Wende des europäischen Krieges, da keine Großmacht mehr bereit war, das Reich Kaiser Karls V. zugunsten seines Nachkommen wiederherzustellen. Die Thronbesteigung Karls VI. brachte die Auflösung der Haager Allianz, weil einerseits die Tories, die die neue Mehrheit im britischen Parlament bildeten, nicht mehr bereit waren, den kostspieligen und sinnlos gewordenen Krieg fortzusetzen und andererseits Ludwig XIV. über einen Ausgleich verhandeln wollte. Das Jahr 1711 erscheint deshalb als das Schicksalsjahr des Spanischen Erbfolgekrieges, weil damals die geheimen Verhandlungen zwischen Versailles und London begannen, Erzherzog Karl ohne irgendwelche Schwierigkeit zum Römischen Kaiser gewählt wurde und die aufständischen Ungarn mit dem Haus Habsburg über einen Ausgleich verhandelten und den Frieden von Szathmar unterzeichneten, was ein Jahrhundert Frieden im Donauraum brachte, einen Frieden, der auf der Basis der Selbständigkeit des Königreiches Ungarn innerhalb der Habsburger Monarchie beruhte. Nach dem Sieg von Villars bei Denain und den schwierigen Unterhandlungen in Holland, die von Lu- 
cien Bély so scharfsinnig analysiert wurden ${ }^{19}$, kamen die Seemächte in Utrecht zu einem dauerhaften Abkommen mit den Bourbonen, wenn auch der kaiserliche Bevollmächtigte, Graf Wratislaw, sich widersetzte, den Frieden abzuschließen; sein Herr blieb aber allein gegen Spanien und Frankreich. Die Niederlagen der Kaiserlichen während des nächsten Feldzugs im Rheinland führten indessen in Wien zu der Einsicht, daß für die von den Seemächten im Stich gelassene Habsburger Monarchie nur noch ein Kompromiß mit Frankreich als das geringere Übel übrig blieb. Dieser Kompromiß wurde durch Prinz Eugen und Feldmarschall von Villars in Rastatt gefunden und vertraglich fixiert.

Der Vertrag von Utrecht beruhte noch auf dynastischer Basis: Großbritannien erkannte Philipp V. als spanischen König unter der Bedingung an, daß er für sich selbst und seine Nachkommen auf alle zukünftigen Rechte auf den französischen Thron feierlich verzichtet. Obwohl diese Verfügung mit den französischen Fundamentalgesetzen kollidierte, wurde der betreffende Vertragsartikel angenommen und im Parlament von Paris registriert. Er galt seither als neues Grundgesetz in Frankreich, so daß jede Personalunion zwischen Spanien und Frankreich völkerrechtlich verboten wurde. Dies war wahrscheinlich das wichtigste Ergebnis des langwierigen Erbfolgekrieges.

$\mathrm{Zu}$ dieser Zeit hatte auch Großbritannien sein eigenes Erbfolgeproblem; Königin Anna, letzter protestantischer Sproß des Hauses Stuart, hatte nämlich kein lebendes Kind mehr, weshalb die Frage ihrer Nachfolge bald gestellt werden mußte. Das englische Parlament und die Mehrheit der führenden Schichten wollten nicht die Rückkehr eines katholischen Stuarts, des damaligen Neffen der Königin Anna, des als Prätendenten bekannten Jakob III., der in seinem französischen Exil von Saint-Germain-en-Laye erzogen wurde. Um die Friedensverhandlungen mit Großbritannien zu erleichtern, wurde er zuerst nach Commercy, im Herzogtum Bar gelegen, gesandt. Anschließend begab er sich von dort ins Exil nach Rom, wo er sein weiteres Leben verbrachte. Geheime Verhandlungen zwischen der Königin und dem Prätendenten scheiterten, weil der Sohn, der auf konfessionellem Gebiet genauso engstirnig wie sein Vater Jakob II. war, offen erklärte, nicht auf seinen Katholizismus verzichten zu wollen, obwohl die alternde Herrscherin ihren Neffen als Nachfolger favorisierte, unter der Voraussetzung, daß der Prätendent den „Act of Settlement“ des Jahres 1701 billige ${ }^{20}$. Deswegen bestätigte Ludwig XIV. im Vertrag von Utrecht die Legitimität der Königin Anna und erkannte die Rechte des Hauses Hannover auf den englischen Thron an. So wurde das Risiko eines weiteren Erbfolgekrieges im voraus vermieden, wenn auch das Problem des jakobitischen Prätendenten für die britische Regierung bis zu der blutigen Niederlage des jungen Prätendenten, „Bonnie Prince Charlie“, auf der Heide von Culloden in Schottland (1746) bestehen blieb. Nach 1714 wurde nämlich die Legitimität des Hauses Hannover von einer Mehrheit von Schotten, von den Iren, aber auch von den englischen Katholiken und von den Tories heftig bestritten, so daß sich die

19 Lucien Bély, Espions et ambassadeurs au temps de Louis XIV (Paris 1990).

20 Ragnbild Hatton, George I Elector and King (London 1978). 
Unzufriedenheit eines Teils der britischen Bevölkerung in der Anzweiflung der Legitimität der Krone artikulierte und die Regierung der Whigs dieses Problem auf internationaler Ebene für sich nützen konnte ${ }^{21}$.

Das französische Kolonialreich wurde aber ein Opfer des diplomatischen Ausgleichs von Utrecht. Obwohl die französische Bevölkerung Kanadas ohne große Schwierigkeiten die englischen Streitkräfte und die amerikanische Miliz noch einmal besiegt hatte, mußte der Sonnenkönig auf bestimmte Hoheitsrechte - nicht auf ganz Kanada -, auf die sogenannte Nova Scotia sowie auf Neufundland zugunsten der britischen Krone verzichten. Spanien hatte den Engländern noch größere Opfer zu bringen. Es mußte die 1704 gefallene Festung Gibraltar, die zum ersten Stützpunkt der „Royal Navy“ im Mittelmeer wurde, das Sklavenhandelsmonopol in Lateinamerika - auch "Asiento" genannt - sowie die italienischen und burgundischen Länder der spanischen Habsburger abtreten. Die Niederlande sollten unter dem Vorbehalt der Errichtung einer holländischen Barriere an den Kaiser zurückgegeben werden, womit den Sicherheitsinteressen der beiden Seemächte entsprochen wurde.

Immerhin brachte der Spanische Erbfolgekrieg Österreich große Gewinne. Wenn auch die damaligen spanischen, nunmehr österreichischen Niederlande vom Wiener Hofe mehr als eine Last denn als eine Verstärkung seiner Position in Westeuropa betrachtet wurden, so wurden die territorialen Ambitionen des Kaisers teilweise durch seine neuen Erwerbungen auf der italienischen Halbinsel kompensiert. Daraus resultierte eine Neuorientierung der habsburgischen Politik. Wien erlangte die Vormachtstellung in Italien durch den Erwerb des Herzogtums Mailand, des Königreiches Neapel und des Königreiches Sizilien, das 1718 gegen Sardinien mit dem Herzog von Savoyen getauscht wurde. Leider verzichtete Philipp V. nie auf die italienischen Besitzungen Spaniens, so wie Kaiser Karl VI. sich lebenslang als spanischer König betrachtete und sich als „auch König in Hispanien" anreden ließ. Noch zehn Jahre Auseinandersetzungen zwischen Wien und Madrid waren notwendig bis zur Versöhnung beider Herrscher. Die Niederlage Österreichs im Polnischen Erbfolgekrieg erlaubte die Rückeroberung Siziliens und Neapels durch spanische Truppen zugunsten des Infanten Don Carlos. Weil Wien nur Mailand sichern und Parma und die Toskana erwerben konnte, wurde die Vormachtstellung der Habsburger nach 1738 auf Norditalien begrenzt. „Die späten Zugewinne im Spanischen Erbfolgekrieg - die südlichen Niederlande, die Herzogtümer Mailand, Mantua und Parma, zeitweilig sogar das süditalienische Königreich - sind mit dem österreichischen Staatsganzen aber nicht mehr verwachsen." 22

Kurfürst Max Emanuel von Bayern bekam trotz aller Versprechungen der französischen Diplomatie keine Entschädigung. Er mußte sich mit der Rückgewin-

${ }^{21}$ Eveline Cruickshanks (Hrsg.), Ideology and Conspiracy. Aspects of Jacobitism 16891759 (Edinburgh 1982). Frank Mac Lynn, The Jacobites (London, New York 1985).

${ }^{22}$ Heinz Schilling, Das Reich und die Deutschen: Höfe und Allianzen. Deutschland 16481763 (Berlin 1989) 307. 
nung seines, von den Kaiserlichen nach der Schlacht von Blenheim eroberten Patrimonialstaates begnügen.

Man mußte mit Bedauern feststellen, daß es einer Art zehnjährigen „Weltkrieges" bedurfte, um die vernünftige Lösung zu erreichen, die schon im großen Bündnis von den Haag vorgesehen gewesen war: die vollkommene Teilung beider Zweige des Hauses Bourbon, damit sich keine übergroße Kolonialmacht entwikkeln konnte, und Kompensationen für die Habsburger, die zu einer bedeutenden Kontinentalmacht in Italien und Mitteleuropa wurden; so hatte man mit Frankreich, dem Kaiser und Großbritannien das europäische Gleichgewicht gerettet, das sich als die Grundlage des europäischen Staatensystems im 18. Jahrhundert herausstellte. Andererseits blieb eine Reihe von dynastischen Problemen ungelöst. Dies gilt vor allem für das absehbare Erlöschen des Hauses Habsburg in männlicher Linie, was nach einem Vierteljahrhundert verhältnismäßig friedlicher Beziehungen in West- und Mitteleuropa zu einer weiteren groß3en Krise führen sollte.

In der Zwischenzeit waren die Großmächte nach so bedeutenden Opfern friedlich gesinnt. Wenn Frankreich finanziell erschöpft war, weil die Staatsschulden mehr als 1 Milliarde Pfund ausmachten, so waren auch die Staatsfinanzen Englands eigentlich nicht in einem viel besseren Zustand. Im letzten Jahr seiner Regierung war Ludwig XIV. sogar bereit, ein Bündnis mit Kaiser Karl VI. zu schlieBen ${ }^{23}$, was der noch wegen des Verlustes von Spanien erbitterte und auch durch Prinz Eugen gegen Frankreich gestimmte Kaiser nicht gerne annahm.

Die Konsolidierung des europäischen Friedens resultierte letztlich aus einem Bündnis Frankreichs mit England, also jencr Länder, in denen die Zukunft beider Herrscher in gleicher Weise gefährdet zu sein schien. Wenn in London die Legitimität König Georgs I. bestritten wurde, so hing in Paris alles an der Gesundheit eines körperlich schwachen Kindes und am guten Willen des Regenten Philipp von Orléans. Im Falle eines frühen Todes Ludwigs XV. war es fraglich, ob sich der König von Spanien an die Verfügungen des Vertrags von Utrecht halten und nicht versuchen werde, den französischen Thron entgegen der Haltung der Anhänger des Herzogs von Orléans zu besteigen; dies hätte zu einem Bürgerkrieg in Frankreich und zu einem europäischen Krieg geführt ${ }^{24}$. Nach 1724 setzte Kardinal Fleury diese Politik der ersten „Entente cordiale“ sorgfältig fort ${ }^{25}$.

Noch während die Westmächte sich bemühten, den teuer erworbenen Frieden gegen die kriegerischen Tendenzen Spaniens und Österreichs zu erhalten, war schon der letzte Habsburger mit einem Erbfolgeproblem konfrontiert. Das neue Hausgesetz beruhte auf der geheim gebliebenen Hausordnung von 1703, die von beiden Söhnen Kaiser Leopolds feierlich anerkannt und unterzeichnet wurde, bevor Erzherzog Karl Wien in Richtung Spanien verlie $\beta^{26}$. Sie wurde von der kaiser-

23 Instruktionen Ludwigs XIV. an Graf du Luc, seinen 1715 ernannten Botschafter in Wien, in: Instructions aux Ambassadeurs, I. Bd., Autriche.

${ }^{24}$ Michel Antoine, Louis XV (Paris 1989).

25 Paul Vaucher, Robert Walpole \& Fleury (Paris 1924).

${ }^{26}$ Dieses Pactum Mutuae Successionis, das bis 1713 geheim gehalten wurde, ist selbstverständlich nicht von G.E. Rinck erwähnt; es wurde abcr als Pragmatische Sanktion publiziert. 
lichen Erklärung von 1713 umgestaltet, die später unter dem Namen der Pragmatischen Sanktion weltberühmt wurde, die praktisch beide Töchter des verstorbenen Kaisers Joseph I. enteignete ${ }^{27}$. Aus seiner im Jahre 1708 mit Elisabeth Christine von Braunschweig-Wolfenbüttel geschlossenen Ehe überlebten nur zwei Töchter, die 1717 geborene Erzherzogin Maria Theresia und die ein Jahr später geborene Erzherzogin Maria Christina. Schon 1720 hatte das kaiserliche Ehepaar nach dem Tod des im Jahr 1716 erstgeborenen Sohnes jede Hoffnung auf männliche Nachkommen verloren. Deshalb bestand der Schwerpunkt der dynastischen Politik Kaiser Karls VI. in der Durchsetzung der allgemeinen Anerkennung der Pragmatischen Sanktion des Jahres 1713. Dieser bedeutende, allerdings stets im Schatten des Prinzen Eugen ${ }^{28}$ stehende Habsburger ist merkwürdigerweise noch zu wenig erforscht. Bis heute verfügen wir über keine wissenschaftliche Biographie $^{29}$.

Die Politik Karls VI. bleibt unklar ${ }^{30}$ : Er hat fast alle seine Kräfte auf die Anerkennung der Pragmatischen Sanktion durch die Großmächte verwendet, die zum Hauptthema seiner Diplomatie nach 1720 wurde: Die Pragmatische Sanktion wurde völkerrechtlich zuerst von Spanien (1725), von Rußland (1726), von Preußen (1728), dann von Großbritannien (1731) und endlich von Frankreich (1738) anerkannt. Kurbayern und Sardinien wollten nichts versprechen. Karl VI. begnügte sich mit der Personalunion aller Königreiche und Länder des Hauses Habsburg und folgte nicht dem ihm schon 1719 vom Prinzen Eugen erteilten Rat, eine Zentralisierung anzustreben und „die Monarchie als ein Totum“ zu formieren. Jedes von seinen herkömmlichen Vorrechten geschützte Kronland blieb nichtsdestoweniger selbständig, was dem System der Vorherrschaft des Hochadels und den politischen Verhältnissen innerhalb der Monarchie entsprach. Italien wurde sogar von cinem sogenannten spanischen Rat separat regiert. Die Fi-

27 „Après la mort de Sa Majesté Impériale (Joseph 1er) sans héritier mâle, ses 'États avaient ćté dévolus ensemble à son frère et ils demeuraient indivisiblement en la possession de l'Empereur actuel pour passer à la descendance masculine et, à défaut de celle-ci, que Dieu veuille l'éviter, à ses filles de légitime mariage, selon l'ordre et le droit de primogéniture. Au cas de l'extinction de la descendance mâle et femelle de Sa Majesté impériale, tous les États et Pays héréditaires passeraient à Mesdames les filles aînées laissées par l'Empereur Joseph 1er, de bienheureuse mémoire, avec tous les avantages et préséances, enfin, en cas d'extinction de la ligne Caroline et de la ligne Joséphine, aux soeurs de sa Majesté l'Empereur et à toutes les autres branches de l'Archimaison." Zitiert in Victor-Lucien Tapié, L'Europe de Marie-Thérèse. Du Baroque aux Lumières (Paris 1972) 31-32.

28 Außer dem Standardwerk von Max Braubach, Prinz Eugen von Savoyen. Eine Biographie, 5 Bde. (München 1963-1965) sind unter den neuesten Biographien des Prinzen Eugen Derek Mc Kay, Prince Eugene of Savoy (London 1977) und Johannes Kunisch (Hrsg.), Prinz Eugen von Savoyen und seine Zeit (Würzburg 1986) zu erwähnen.

${ }_{29}$ Brigitte Hamann (Hrsg.), Die Habsburger. Ein Biographisches Lexikon (Wien 1988) Art. Karl VI. von Volker Press, 215-219. Siehe auch den Beitrag von Hans Schmidt, in: Anton Schindling, Walter Ziegler (Hrsg.), Die Kaiser der Neuzeit 1519-1918 (München 1990) 200214.

${ }^{30}$ Jean Bérenger, Histoire de l'Empire des Habsbourg, 1273-1918 (Paris 1990, dt. Übersetzung. Wien 1995). 
nanzen wurden auch nicht vereinigt, und nur das kaiserliche Heer blieb fest in der Hand des Wiener Hofes. Die Pragmatische Sanktion war zwar ein positiver Schritt, weil sie von jedem Landtag feierlich anerkannt wurde. Sie bildete zum Beispiel die feste Grundlage der Union mit Ungarn. Sie reichte aber nicht dafür aus, um im Notfall die zersplitterten Kräfte der Monarchie rasch zu mobilisieren. Die Krise von 1740 hat erkennen lassen, wie locker die Bindungen zwischen den Untertanen der Monarchie geblieben waren.

Genauso unvorsichtig erschien die kaiserliche Heiratspolitik, weil Karl VI. sehr früh den jungen Herzog Franz III. von Lothringen, der 1727 seinem Vater Leopold nachgefolgt war, als Schwiegersohn und richtigen Nachfolger behandelte. Der Kaiser schien aber nicht erkannt zu haben, daß solch ein Heiratsplan von der französischen Regierung als eine Herausforderung betrachtet wurde, weil das Habsburger Reich sich im Gefolge der Realisierung dieses Planes bis zur $250 \mathrm{~km}$ von Paris entfernten Stadt Bar le Duc erstrecken und die französische Hauptstadt bedrohen würde. Alle Bemühungen der französischen Regierungen, die lothringische Frage durch einen Kompromiß zu lösen, erschienen von neuem zum Scheitern verurteilt, weil die im Rijswijcker Frieden errungene Neutralität Lothringens damit in Frage gestellt wurde. „Die erste Ursache des Krieges lag in der Entscheidung Karls VI., die Hand seiner Erbtochter dem Prinzen Franz von Lothringen zu geben. Lothringen mit Österreich vereint, sollte der französischen Interessensphäre entzogen werden und zur Stärke des Kaisers im Reich beitragen. "31 Die Angst des damaligen französischen Regierungsschefs, Kardinal Fleury ${ }^{32}$, hat dazu beigetragen, die polnische Erbfolgekrise zu verschärfen ${ }^{33}$.

Der Ursprung des Polnischen Erbfolgekrieges lag nach dem plötzlichen Tod König Augusts II, in der schwankenden Haltung Rußlands und seines Verbündeten Österreich. Beide waren nicht bereit, die Kandidatur des Sohnes Augusts II., des sächsischen Kurfürsten Friedrich August, zu unterstützen. Sie erklärten sich zuerst zugunsten der Wahl eines Piasten, $d$. h. eines polnischen Magnaten, was einer neuen Kandidatur Stanislaus Leszczynskis die Tür öffnete. Für die französische Seite war es aber nicht das Hauptziel des Krieges, den im französischen Exil

31 Heinrich Benedikt, Finanzen und Wirtschaft unter Karl VI., in: Der Donauraum 9 (Wien 1964) 46.

32 Kardinal Fleury (1653-1743) war im Grunde genommen ein friedlicher Staatsmann, der 20 Jahre lang als Erster Minister Frankreichs fungierte. Bürgerlicher Abstammung wurde er erst 1683 Bischof von Fréjus und profitierte vom Vertrauen Ludwigs XIV. und Madame de Maintenons. Deshalb wurde er zum Erzieher des zukünftigen Ludwig XV. Er hatte einen positiven Einfluß auf die königliche Waise, die immer Vertrauen zu ihm hatte. Deshalb überließ Ludwig XV. ihm bis zu seinem Tod eine führende Rolle im königlichen Rat. Fleury hatte gute Beziehungen zum britischen Premierminister Walpole und wollte um jeden Preis das Bündnis mit England retten, wenn er auch nach 1738 eine Annäherung an Österreich wünschte, um das europäische Gleichgewicht zu festigen. Leider war dieser begabte Staatsmann schwach und nach 1740 zu alt.

33 Zum Polnischen Erbfolgekrieg siehe auch Jean Bérenger, Jean Meyer, La France dans le Monde au XVIII ${ }^{\circ}$ siècle (Paris 1993) 6. Kapitel: La guerre de Succession de Pologne (17331738): aspects orientaux et problème lorrain: les traités de Vienne. 
lebenden Stanislaus Leszczynski wieder auf den Thron zu bringen, sondern eine für die französische Sicherheit annehmbare Regelung der lothringischen Grenzfrage zu finden. Schon am Anfang des Krieges wurde das Herzogtum von Feldmarschall von Belle-Isle ${ }^{34}$ besetzt und durch ein Abkommen mit der Regentin Elisabeth Charlotte, der Mutter des schon in Wien lebenden Herzogs Franz III., im Oktober 1733 für neutral erklärt ${ }^{35}$.

Die zwei für die kaiserlichen Streitkräfte wenig erfolgreichen Feldzüge im Rheinland ermöglichten nach Verhandlungen in Den Haag einen Ausgleich mit dem Engländer Waldegrave, in Rom und in Wien mit Sinzendorf zu finden (Präliminarvertrag von Wien, Oktober 1735). Infolge des erwarteten Ablebens von Giovanni Gastone, des letzten männlichen Sprößlings des Hauses Medici, das in Florenz seit dem XVI. Jahrhundert herrschte ${ }^{36}$, hat man an einen Austausch gedacht: die Toskana gegen Lothringen. Dieses Verfahren bot manche Vorteile. Einmal wäre dic Erbfolgefrage in der Toskana sofort nach dem Tod Giovanni Gastones gelöst worden, zum anderen hätten noch zwei zusätzliche Probleme geregelt werden können: Erstens hätte der Schwiegervater Ludwigs XV. eine ehrenvolle Kompensation bekommen. Statt in dem goldenen Exil von Chambord weiterzuleben, was für das Ansehen des Allerchristlichen Königs schädlich war, hätte Stanislaus Leszczynski eine eigene souveräne Herrschaft erlangt und auf diese Weise seine königliche Würde gewahrt ${ }^{37}$. Auf diese Weise hätte man das polnische Abenteuer am günstigsten für Frankreich ${ }^{38}$, die Familie Leszczynski, die Wettiner und dic Adelsrepublik erledigt. August III. wurde von Frankreich anerkannt, bevor er engere Bindungen mit Versailles einging und Anspruch auf die Habsburger Erbschaft im Namen seiner Gattin erhob. Für Karl VI. bedeutete der Erwerb der Toskana eine Kompensation für den Verlust beider Sizilien im Jahre 1735 nach den Niederlagen der Kaiserlichen auf der Halbinsel und der Eroberung Neapels und Palermos durch die spanischen Truppen. Scin Machtbereich wurde durch den Gewinn Parmas, dic Kontrolle der Toskana und die Beibehaltung des größten Teils des Herzogtums Mailand nach dem Norden der Halbinsel verlagert. Österreich konnte auf diese Weise seine Vormachtstellung in Italien, die den Habsburgern so am Herzen lag, bestätigen. Die Sicherheit der französischen Ostgrenze wurde für

34 F.-A. Chevrier, Vie politique et militairc du Maréchal de Belle-Isle (Den Haag 1762). Belle-Isle war der Enkel des berühmten Oberintendanten der Finanzen Fouquet, der 1661 in Ungnade fiel. Ludwig XIV. erlaubte dem begabten Enkel, ein Dragonerregiment zu kaufen. So begann die hervorragende Militärlaufbahn von Belle-Isle.

35 Jean Bérenger, Le maréchal de Belle-Isle, général et homme d'Etat à l'époque des Luimières (1684-1761), Soldiers-Statemen of the Age of the Enlightenment, Commission Internationale d'Histoire militaire, Acta $n^{\circ} 7$ (Washington D.C. 1982) 181-210.

36 Jean-Claude Waquet, Le Grand Duché de Toscane sous les derniers Médicis (Paris 1990).

37 Er wurde durch dic Vermittlung Kaiser Karls VI. förmlich zum zweiten Mal als polnischer König anerkannt und dankte anschließend $\mathrm{ab}$, so daß er lebenslang den königlichen Titel führen durfte.

${ }^{38}$ Die Tatsache, daß die regierende Königin von Frankreich, Maria Leszczynska, die Tochter eines poinischen Magnaten war, wurde von der öffentlichen Meinung als nicht standesgemä13 betrachtet. 
die Zukunft ausgebaut und die lothringische Frage endlich gelöst, da das Herzogtum nach dem Tod König Stanislaws dem Königreich angegliedert werden sollte, was ohne Schwierigkeit im Jahre 1766 geschah. Auf diese Weise wurde auch der Standpunkt des Kanzlers Ludwigs XIV., Pontchartrain, bestätigt, den jener seinerzeit in Frage der spanischen Erbfolge eingenommen hatte: Mit der Annahme des Testaments von Karl II. konnte man beide Fragen im Sinne der strategischen Interessen Frankreichs lösen, d. h. die Versöhnung mit Spanien und die Sicherung der französischen Nordostgrenze erreichen. Der am meisten zurückhaltende Partner blieb trotzdem Herzog Franz III. von Lothringen, später in Wien als Franz Stephan von Lothringen bekannt. Obwohl er die Vermählung mit der Erzherzogin Maria Theresia und die Wahl zum zukünftigen Kaiser als Nachfolger des letzten Habsburgers leidenschaftlich anstrebte, war er nicht bereit, auf seinen $\mathrm{Pa}$ trimonialstaat so leicht zu verzichten. Bis 1736 machte er Schwierigkeiten, das Wiener Abkommen anzunehmen. Nur unter dem Druck Kaiser Karls VI., der ihm die Hand Maria Theresias so lange verweigerte, bis er prinzipiell den Verzicht auf Lothringen billigte, wurde der Ausgleich gerettet. Der Tod Großherzog Giovanni Gastones im Jahre 1737 ermöglichte 1738 die Durchführung des Tauschprojektes. Der Friedensschluß mit Frankreich wurde 1737 durch die Ungnade des damaligen Staatssekretärs und zum Kanzler beförderten Chauvelin erleichtert, welcher sich indessen als der Leiter der antihabsburgischen Partei in der Regierung und in der schon wichtig gewordenen öffentlichen Meinung behauptete ${ }^{39}$.

Die zurückhaltende Bevölkerung Lothringens, die im Gegensatz zu der positiv betrachteten Regierungszeit des Herzogs Leopold (1697-1729) bittere Erinnerungen an dic französische Besatzung des vergangenen Jahrhunderts hattc, sah dic endgültige Abfahrt seines legitimen Herrschers nach Wien ${ }^{40}$ ebenso mit Wehmut wie den Rückritt der Regentin in Schloß Commercy ${ }^{41}$.

Franz Stephan weilte 1739 kurze Zeit in Florenz und überließ die Verwaltung der Toskana einem Beauftragten, dem Grafen von Renoncourt, der übrigens bei den Florentinern genauso wenig beliebt war wie sein Herr. Erst später, von 1765 bis 1790 , regierte sein zweitgeborener Sohn, Erzherzog Leopold, die Toskana persönlich. König Stanislaus bot seinen neuen Untertanen einen milden Übergang in die wenig gewünschte Herrschaft Frankreichs. Dieses führte zwar durch das Abkommen von Meudon schon 1738 seine Verwaltung ein, aber der als königlicher Kanzler in Nancy fungierende Intendant La Galaizière war ein fähiger und ehrlicher Beamter, der die gelegentlichen Reibungen mit der Bevölkerung mit mehr

39 Lucien Bély, Relations internationales en Europe (Paris 1992) 480.

40 „En un temps où le mot et le mythe d'autodétermination n'existaient pas, leur sort résultait d'un jeu diplomatique adroit, étranger à la volonté des peuples et réglé par les convenances des princes, mais la désertion de leur dynastie séculaire désarmait leur patriotisme. Aussi bien fût-ce avec une morne indifférence qu'ils accueillirent leur nouveau maître", Michel Antoine, Louis XV, 347.

${ }^{41}$ Collin Hubert, François-Étienne dernier duc de Lorraine et premier empereur de la maison des Habsbourg-Lorraine, in: J.-P. Bled, R. Faucher, R. Taveneaux (Hrsg.) Les Habsbourg et la Lorraine (Nancy 1988) 151-159. 
Geschick behandelte als seine Vorfahren im 17. Jahrhundert. Vor allem wurde das französische Steuersystem eingeführt. Der dem Haus Lothringen treu gebliebene Adel (ca. 700 Menschen) wanderte nach Wien oder Florenz aus, wo er seine Talente in den Dienst Franz Stephans stellte und zur Verbreitung der französischen Kultur beitrug. Der zum ersten Mal in seinem Leben reiche König Stanislaus, welcher über eine jährliche Pension von ca. 2 Millionen Pfund verfügte, konnte Nancy zu einer üppigen Residenzstadt verwandeln, wohingegen die Entschädigung, die Franz Stephan von Frankreich in bar bezahlt wurde, die Basis für das zukünftige habsburg-lothringische Privatvermögen darstellte ${ }^{42}$.

Der Wiener Vertrag von 1738, der den Untergang Polens als europäische Macht zusätzlich bestätigte ${ }^{43}$, darf als ein Meisterwerk der damaligen Diplomatie bezeichnet werden. Als erster hatte König Friedrich Wilhelm I. von Preußen den Tausch Lothringens gegen die Toskana zugunsten Stanislaus', den er nach der Danziger Belagerung im königlichen Schloß Königsberg 1734 beherbergte, vorgeschlagen. Sein Sohn, Friedrich II., war 1738 der Meinung, daß die Stellung Frankreichs in Europa besondere Vorteile habe: „Depuis la paix de Vienne, la France était l'arbitre de l'Europe ${ }^{* 44}$, was sich u. a. darin manifestierte, daß Kardinal Fleury eine Annäherung an Österreich anstrebte und den französischen Botschafter in Wien aufforderte, „à se faire l'instrument de ce qui se peut opérer de plus intéressant pour l'Europe entière, l'établissement d'une intelligence et d'une union aussi durables qu'intimes entre le roi et l'Empereur" ${ }^{* 45}$.

Leider war der Krieg mit dem Osmanenreich (1737-1739) ein schwerwiegender Prestigeverlust für die Monarchie. „Die Schwäche der habsburgischen Armee, deren Modernisicrung Prinz Eugen zuletzt sträflich vernachlässigt hatte, war nicht mehr zu verheimlichen - ein schlechtes Vorzeichen für den täglich zu erwartenden Kampf um die Sicherung der weiblichen Thronfolge, die einige der europäischen und deutschen Mächte nur halbherzig, andere gar nicht anerkannt hatten. " ${ }^{\text {c6 }}$

Zwei Jahre später begann die schlimmste Krise, die das Haus Habsburg je erlebt hatte: der Österreichische Erbfolgekrieg ${ }^{47}$. So wie beim Spanischen Erbfolgekrieg schien am Anfang alles ruhig zu bleiben, und Kardinal Fleury erklärte im Dezember 1740 dem kaiserlichen Botschafter in Paris, daß Ludwig XV., der persönlich für die französische Neutralität eintrat ${ }^{48}$, seine 'Versprechungen halten werde.

${ }^{42}$ Hanns-Leo Mikoletzky, Kaiser Franz I. Stefan und der Ursprung des habsburgisch-lothringischen Familienvermögens (München 1961).

${ }_{43}$ Michael G. Müller, Polen zwischen Preußen und Rußland. Souveränitätskrise und Reformpolitik (Berlin 1983).

${ }^{44}$ Friedrich der Große, Réflexions politiques, 1738, zitiert von Michel Antoine, Louis XV, 300.

${ }^{45}$ Zitiert von Gaston Zeller, Histoire des relations internationales. Les temps modernes, Bd. III (Paris 1955) 191.

46 Scbilling, Das Reich und die Deutschen: Höfe und Allianzen, 286.

47 J. Bérenger, J. Meyer, La France dans le Monde au XVIII ${ }^{\circ}$ siècle (Paris 1993), 7. Kapitel: La guerre de Succession d'Autriche (1740-1748).

${ }^{48}$ Ludwig XV. behauptete damals: „Je ne veux pas dans cette circonstance me mêler de rien, je demeurerai les mains dans les poches, à moins que l'on ne voulût élire un protestant empe- 
Dies war aber nicht die Meinung der anderen Staatsminister, und die antihabsburgische Partei blieb genauso stark wie zur Zeit des Polnischen Erbfolgekriegs. Auch Kardinal Fleury war im Grunde genommen genauso schwankend wie früher. Er war insbesondere überzeugt, daß Franz Stephan von Lothringen, der wahrscheinlich zukünftige Römische Kaiser, noch franzosenfeindlicher als zuvor sein würde, so daß er sich für den Verlust Lothringens rächen und nach der Kaiserwahl das ganze Reich mobilmachen werde, um seinen Patrimonialstaat zurückzuerobern. Deswegen favorisierte Frankreich eine Kandidatur des bayerischen Kurfürsten Karl Albrecht von Anfang an, obwohl es zuerst die Integrität der Habsburger Monarchie aufrecht erhalten wollte. Nachdem der Kanzler Chauvelin in Ungnade gefallen war, wurde der Feldmarschall von Belle-Isle, Statthalter von Metz, der neue Leiter der österreichfeindlichen Partei. Im Februar 1741 überzeugte Belle-Isle Kardinal Fleury, der nach dem preußischen Einfall in Schlesien gegenüber dem jungen Friedrich II. sehr zurückhaltend war ${ }^{49}$, davon, in Deutschland zu intervenieren. Eigentlich entstand die Katastrophe für Maria Theresia weniger aus der unfreundlichen Haltung der französischen Regierung als aus dem unerwarteten Einfall Friedrichs des Großen in Schlesien und aus den Ansprüchen Kursachsens und Kurbayerns.

Zu den zahlreichen Fehlern, die Kaiser Karl VI. beging, kann man die Heiratspolitik seiner Nichten, der Töchter des verstorbenen Kaisers Joseph rechnen. Schon im Jahre 1719 heiratete Erherzogin Maria Josepha den sächsischen Prinzen Friedrich August, den zukünftigen König von Polen, August III. Drei Jahre später vermählte sich ihre Schwester Maria Amalia mit dem bayerischen Kurprinzen Karl Albrecht. Beide Erzherzoginnen leisteten den üblichen Verzicht auf die Habsburger Erbschaft, aber jeder wußte, daß diese Verträge keinen besonderen Wert hatten, vor allem für Max Emanuel von Bayern, der schon in dieser Heirat die Revanche für seine Mißerfolge während des Spanischen Erbfolgekriegs sah. 1722 gab er 4 Millionen Gulden für die Münchener Heiratsfeicrlichkeiten seines Sohnes aus, um der öffentlichen Meinung Deutschlands zu zeigen, wer der nächste Kaiser sei. Kurbayern und Kursachsen hatten indessen ausgezeichnete Motive, sich in die Nachfolgefrage cinzumischen, weil sie behaupten konnten, daß ihre Gattinnen von der Pragmatischen Sanktion enterbt worden seien. Max Emanuel hatte seit 1720 sein Bündnis mit Frankreich erneucrt, um Subsidien von Versailles zu bekommen, die dem Unterhalt seines Hecres dienen sollten.

Bald erschien die Zukunft der Monarchie aussichtslos. Die preußischen Soldaten wurden ausnahmsweise als Befreier von der Bevölkerung Schlesiens begrüßt, weil eine cindeutige Interpretation des Westfälischen Friedens durch die Habsburger cine Erweiterung der Rekatholisierung nach 1680 erlaubt und dauerhafte

reur“ und einige Wochen später: „Nous n'avons qu'une chose à faire, c'est de rester sur le Mont Pagnote." Zitiert in: Antoine, Louis XV, 301.

49 Fleury zeigte seine Genugtuung "devant l'heurcuse circonstance que présentait à la France l'extinction du dernier mâle de la Maison d'Autriche, mais marqua le peu de fonds qui'il faisait sur le caractère de ce prince Frédéric II“. Belle-Isle, Ungedruckte Memoiren, Bibliothèque Nationale, Paris, Handschriftensammlung, Ms fr. 11.254, $\mathrm{f}^{\circ} 3$. 
Unzufriedenheit bei den Evangelischen Niederschlesiens verursacht hatte. Die Festungen Brieg und Großglogau waren menschenleer, und die Preußen stießen praktisch auf keinen Widerstand, so daß die Eroberung Schlesiens in zwei Monaten abgeschlossen war. Friedrich II., der einige Rechte auf drei Fürstentümer geerbt hatte, verlangte die Herausgabe des ganzen Herzogtums. Dafür versprach er, anläßlich der kommenden Kaiserwahl, die brandenburgische Kurstimme Franz Stephan zu geben.

Karl Albrecht, der seine Rechte aus dem Testament Kaiser Ferdinands I. (1564) ableitete, beanspruchte noch mehr: das Königreich Böhmen und die Kaiserkrone. Er fand bald die französische Unterstützung, denn die Pariser Kriegspartei sah eine unverhoffte Gelegenheit, das Haus Habsburg zu erniedrigen ${ }^{50}$ und einen franzosenfreundlichen Kaiser im Reich zu etablieren, ohne einen Augenblick zu befürchten, das ganze Gleichgewicht Mitteleuropas umzustürzen. Belle-Isle und seine Anhänger waren nämlich der illusorischen Meinung, daß die Klientel des Allerchristlichen Königs von dieser großen Umwälzung profitieren würde ${ }^{51}$. Wenn Fleury ursprünglich nur das defensive Bündnis mit Kurbayern bestätigen und diplomatisch den Kurfürstentag beeinflussen wollte, ließ er sich bald von Belle-Isle, der von der öffentlichen Meinung unterstützt wurde, überreden, und ohne formell den Krieg zu erklären, schickte er im Sommer 1741 ein Hilfskorps ${ }^{52}$ von 40.000 Mann (47 Bataillonen und 90 Schwadronen) nach Bayern, das im Herbst Linz erreichte. Frankreich wurde also noch einmal in einen Krieg auf dem Festland verwickelt, als schon das Risiko bestand, in Nordamerika ${ }^{53}$ in Auseinandersetzung mit England ${ }^{54}$ zu geraten. Die ganze Politik Kardinal Fleurys beruhte auf dem bayerischen Bündnis ${ }^{55}$, obwohl der bayerische Staat nicht so mächtig wie im 17. Jahrhundert war und die sich jährlich auf bis zu 800.000 Gulden erstreckenden Subsidien, die von Frankreich gezahlt wurden, mehr für Hofausgaben als für

50 Lucien Bély, Relations internationales, 491. Antoine, Louis XV, 300-309.

51 Das Ziel von Belle-Isle, das bald auch von der französischen Regierung akzeptiert wurde, war „abaisser la Maison d'Autriche en lui ôtant d'une part la couronne impériale et la faisant passer avec une partie de ses possessions sur la tête de l'Électeur de Bavière, ce qui est si glorieux au roi, si honorable au ministère de son Éminence que l'on ne peut trop y réflechir et prendre assez de mesures pour assurer le succès“. Belle-Isle, Mémoires, $f^{\circ} 24$.

52 Da es keinen Kriegszustand zwischen Frankreich und der „Königin von Ungarn“ gab, haben die Franzosen als Hilfstruppen von Kurbayern und nicht als Soldaten des Allerchristlichen Königs gekämpft.

53 Nach Saint-Simon verwickelte Belle-Isle die Regierung „dans la plus cruelle guerre, en laquelle le cardinal Fleury s'est imbécilement laissé engager par l'intérêt d'un très simple particulier, qu'il haïssait, et dont il se défiait". Mémoires pour l'année 1718 (erst 1745 aufgeschrieben), G. Truc (Hrsg.), Bd. V, 1314.

${ }^{54}$ Spanien war schon seit 1739 wegen Kolonialinteressen in Konflikt mit Großbritannien geraten.

55 Es beruhte auf einer Reihe von Abkommen (1727, 1733 und 1738) mit Zahlung von Subsidien, die $30 \%$ der Militärausgaben Bayerns deckten und seit 1738 im Gegensatz zu dem Wiener Vertrag erscheinen. Über die Subsidien von Versailles siehe Peter-Claus Hartmann, Karl Albrecht - Karl VII. Glücklicher Kurfürst, Unglücklicher Kaiser (Regensburg 1985) 151-155. 
die Unterhaltung des vorgesehenen Heeres von 40.000 Mann verwendet worden waren. Deshalb verfügte Karl Albrecht 1740 nicht über die erforderlichen Mittel für seine durchaus ambitiöse Politik. Ludwig XV. hatte sein Geld umsonst ausgegeben $^{56}$.

Friedrich II. agierte bereits als Anführer der antihabsburgischen Aktion, wohingegen die anderen Herrscher als schwache Mitläufer erschienen. Nach dem preußischen Sieg bei Mollwitz änderte Frankreich seine Pläne vollkommen; anstatt die Kaiserwahl Karl Albrechts zu favorisieren und die Habsburger Monarchie zu retten, begünstigte auch Fleury unter dem Einfluß von Belle-Isle die Teilung der Erbschaft von Maria Theresia. Im September 1741 wurde von Belle-Isle in Frankfurt ein Vertrag geschlossen, dessen Verwirklichung den Untergang der Monarchie und reinen Unsinn vor dem Hintergrund der damaligen Diplomatie und des europäischen Gleichgewichts bedeutete. August III. sollte Mähren, Oberschlesien und das Waldviertel (Niederösterreich nördlich der Donau) annektieren, um eine direkte Verbindung zwischen seinem Patrimonialstaat Kursachsen und der Republik Polen herzustellen, und Karl Albrecht wurde gestattet, sich sofort der Gebiete von Vorderösterreich, Tirol, Oberösterreich und des Königsreichs Böhmen zu bemächtigen. Der im September 1741 zwischen Karl Albrecht und Philipp V. geschlossene Vertrag von Nymphenburg sicherte noch Kurbayern die Unterstützung Spaniens, das mit Hilfe von französischen Truppen die italienischen Länder des Erzhauses zurückerobern sollte. Maria Theresia blieb nur das Königreich Ungarn übrig, was mit Kroatien und Siebenbürgen ein 320.000 Quadratkilometer breites, wenig bevölkertes (ca. 6 Millionen Einwohner) und noch am Rande Europas liegendes Land dargestellt hätte. Dieser Rest bot keine Basis mehr für eine Großmacht. Nur auf die Toskana und Ungarn gestützt, wäre das Haus Habsburg-Lothringen in der Tat auf die Stufe einer zweitrangigen Macht herabgedrückt und die Landkarte Mitteleuropas vollkommen umgewandelt worden. Karl Albrecht verfügte über ein mächtiges Bündnis, das aus Frankreich, Kursachsen, das auch ein Hilfskorps von 18.000 Mann nach Böhmen zu schicken versprochen hatte, Kurköln (sein Bruder war Erzbischof Clemens August) und Kurpfalz bestand. Der eher zurückhaltende Mainzer Kurfürst Philipp Karl von der Eltz sah sich gezwungen, den Kurfürstentag nach Frankfurt einzuberufen, damit das Kurkolleg aus den drei Kandidaten - nämlich Franz Stephan von Lothringen, Karl Albrecht und August III. - einen neuen Kaiser wählte.

Zu dieser Zeit hätte Flcury noch die unvernünftige Politik Frankreichs ändern und zu der vorsichtigen Haltung vom Dezember 1740 zurückkehren können, weil Maria Theresia den kaiserlichen Hofrat Koch nach Paris schickte, um Karl Albrecht die Niederlande, Italien und Luxemburg gegen den garantierten Besitz Böhmens anzubieten. Belle-Isle, der sich ungeheuer leichtsinnig zeigte, ließ aber

56 „Je ne sais par quelle négligence nous n'avions point eu de ministres à Munich depuis près de dix ans; au moyen de quoi l'on ignorait à Versailles que l'Électeur de Bavière n'avait ni ministres, ni généraux, ni troupes, ni magasins, ni arsenaux et que ses finances étaient dans un tel désordre que l'on n'en pouvait tirer aucune espèce de ressources." Belle-Isle, Mémoires, Ms fr. 11.254, $\mathrm{f}^{\circ} 34$. Die Subsidien wurden schon ab 1737 von 800.000 auf $270.000 \mathrm{fl}$ reduziert. 
Koch antworten, daß „die Königin wirklich und absolut ohnmächtig“ sei. Fleury unterbrach die geheimen Verhandlungen, als Maria Theresia nach der Krönung in Preßburg die finanzielle und militärische Hilfe des ungarischen Adels, der ihr 100.000 Mann versprach, bekommen und einen ersten Waffenstillstand mit Friedrich II. in Klein-Schellendorf geschlossen hatte. Weil sie Schlesien opferte, versprach der preußische König, bei der Kaiserwahl die kurbrandenburgische Stimme dem Herzog der Toskana zu geben. „Die Königin von Ungarn“ konnte deshalb ihre gesamten militärischen Kräfte gegen Karl Albrecht richten, der mit seinen Truppen und dem französischen Hilfskorps in Böhmen einmarschierte, anstatt sich der wehrlosen Residenz Wien zu bemächtigen ${ }^{57}$. Ein Sturmangriff ermöglichte zwar Belle-Isle und seinen Soldaten, am 26. November 1741 Prag zu erobern und Karl Albrecht die Krönung zu verschaffen. Die Eroberung Böhmens durch die Franzosen war aber militärisch dennoch ein Unsinn, obwohl der bayerische Kurfürst die baldige Huldigung des böhmischen Hochadels und die Unterstützung der Bevölkerung bis zur Rückkehr der österreichischen Soldaten im Frühjahr 1742 erlangte. Die von der Hauptarmee völlig getrennten französischen Truppen besetzten ein Jahr lang die böhmische Hauptstadt, ehe ein Rückzug nach Eger die französische Garnison von Prag rettete.

Im Januar 1742 endlich wurde Karl Albrecht cinstimmig zum Kaiser gewählt, der, nach dem Urteil Voltaires „durch seinen Aufstieg zu einem der unglücklichsten Herrscher der Erde wurde“. Auf jeden Fall hat seine Politik den endgültigen Zusammenbruch der europäischen Stellung Bayerns verursacht. Für P. C. Hartmann $^{58}$ beruht der Mißerfolg Kaiser Karls VII. auf der ungenügenden Unterstützung, die Frankreich ihm nach 1742 gewährte. Das Diarium Karl Albrechts zeigt: Er war kein schlechter Herrscher, blieb bis zum Ende chrlich, aber er wurde von Feldmarschall de Broglie ungenügend unterstützt. Seine Thronbesteigung, die einen jahrhundertelangen Traum des Hauses Wittelsbach verwirklichte, bewies noch einmal, daß die Kaiserwürde ohne eigene Hausmacht eine Illusion blieb und daß der Landesherr einer deutschen Mittelmacht wie Kurbayern (oder Kursachsen) nicht imstande war, eine selbständige Politik zu betreiben.

Friedrich II. verließ die Koalition ${ }^{59}$, sobald er mit dem Berliner Vertrag (Juli 1742) erreicht hatte, was er wünschte, d. h. den Anschluß Schlesiens (mit Ausnahme der drei oberschlesischen Fürstentümer Teschen, Jaegerndorf und Troppau) und der Grafschaft Glatz an die preußische Monarchie. Das Herzogtum Schlesien, ein Lehen der böhmischen Krone, war eine der am meisten bevölkerten und reichsten Provinzen des Habsburger Reiches: Es zählte ca. 1 Million Einwohner und bezahlte $11 \%$ der Steuern, die von der Wiener Hofkammer cinkassiert

\footnotetext{
57 Tapié, L'Europe de Marie-Thérèse, 60-67.

58 Hartmann, Karl Albrecht - Karl VII., 306-310.

59 Friedrich II., der ein erstes Mal seine Pläne geändert hatte, verweigerte Franz Stephan bei der Kaiserwahl 1742 seine Stimme und griff Maria Theresia in Böhmen an, was die Situation der Franzosen in Prag eine Zeit lang erleichterte. Unter dem Druck von Lord Carteret sah sich Maria Theresia im Sommer 1742 ein zweites Mal gezwungen, mit der Hoffnung auf eine baldige Revanche, Schlesien Friedrich II. abzutreten.
} 
wurden. Es erzeugte Tücher, die über Hamburg bis nach Lateinamerika exportiert wurden. Der Verlust Schlesiens bedeutete also für Maria Theresia eine dauerhafte Schwächung ihrer wirtschaftlichen und militärischen Macht, die nie ausgeglichen werden konnte. Es war um so schlimmer, als die geographische Lage Schlesiens Friedrich II. erlaubte, leichter in Böhmen und Mähren einzugreifen und sogar Wien zu bedrohen. Der Erwerb Schlesiens brachte Preußen auf einmal 1 Million Menschen und der Staatskasse viel Geld. Preußen hörte plötzlich auf, eine deutsche Mittelmacht so ähnlich wie Bayern oder Kursachsen zu sein. Es stieg zu einer europäischen Macht auf.

An und für sich wurde seit 1742 das Gleichgewicht in Mitteleuropa zugunsten Preußens und zum Schaden Österreichs geändert. Die englische Unterstützung Österreichs erfolgte um diesen Preis, denn Lord Carteret, der jetzt für die britische Politik verantwortlich war, bezahlte Maria Theresia beträchtliche Subsidien nur unter gewissen Bedingungen. Zu diesen gehörte die Forderung, sich mit Preußen zu versöhnen. Wenn diese enge Verbindung Österreichs mit England die Habsburger Monarchie rettete, trug sie auch dazu bei, ganz Europa einen deutschen Konflikt zu bescheren. Was Fleury vermeiden wollte, trat ein. Der Vertrag, der zwischen Savoyen und Maria Theresia geschlossen wurde, enthüllte im September 1743 die Kriegsziele der „Königin von Ungarn“. Sie überließ dem König von Sardinien, der endlich die Pragmatische Sanktion anerkannte, einen Teil des Herzogtums Mailand. Als Gegenleistung sollte sie das Elsaß und das Herzogtum Lothringen mit den drei Bistümern annektieren. Dieser Plan war genauso unvernünftig wie der Teilungsplan für die Monarchie aus dem Jahre 1741. Er zeigte aber, daß das Haus Habsburg-Lothringen nicht auf seinen Patrimonialstaat verzichtet hatte. Der Wormser Vertrag rechtfertigte gewissermaßen die Politik Fleurys von 1733 und 1741: Franz Stephan blieb ein gefährlicher Nachbar der Krone Frankreichs.

Karl VII. befand sich bald in einer ähnlichen Situation wie sein Vater Max Emanuel während des Spanischen Erbfolgekrieges: Bayern wurde von den österreichischen Truppen unter der Führung des Grafen Khevenhüller, eines Enkels Montecuccolis, erobert ${ }^{60}$, und der neue Kaiser konnte nicht mehr nach München zurück. Erst 1744 erfolgte der französische Gegenstoß. Vor allem ein neuer Angriff Friedrichs II. erlaubte es einer aus hessischen, preußischen und bayerischen Kontingenten bestehenden Armee, in Süddeutschland einzumarschieren. Sie zwang Karl von Lothringen, den Oberbefehlshaber der österreichischen Truppen ${ }^{61}$, nach Mähren zurückzukehren. So wurde München von der österreichischen Besatzung befreit, wo Kaiser Karl VII. endlich seinen Einzug halten konnte.

In diesen schweren Stunden stützte sich Maria Theresia auf die britische Hilfe, die ihr zugleich die nötigen Subsidien und eine Diversion in den Niederlanden

60 Die aus den in Italien stehenden Regimentern gebildete Armee befreite Linz schon am 23. Januar 1742 und marschierte in München am 12. Februar ein.

${ }_{61}$ Bis 1745 darf man nicht mehr von „kaiserlichen“ reden, und der Ausdruck „Pragmatische Armee" war damals üblich für die Truppen Maria Theresias. 
verschaffte. Das englische Kabinett zwang aber Maria Theresia gegen ihren Willen, Schlesien zweimal (1742 und 1745) an Friedrich II. abzutreten. Infolgedessen richtete diese ihre Gesamtpolitik darauf aus, die verlorene Provinz zurückzuerobern oder später dafür eine Kompensation in Osteuropa zu erlangen, die dann Österreich gegen Schlesien zu tauschen gedachte.

Der Anschluß Schlesiens war der Anfang der preußischen Großmachtbildung und bedeutete die Schaffung eines neuen Gleichgewichts in Deutschland. Bis jetzt hatte man ein Römisches Reich, dessen Kaiser der oberste Herr aller Fürsten blieb, und König Friedrich Wilhelm I. hatte sich immer als ein treuer Vasall Kaiser Karls VI. verstanden. Friedrich der Große betrachtete sich von vornherein als der Regent eines völlig souveränen Staates, der nur gezwungenermaßen dem Kaiser die Huldigung für die deutschen Lehen leistete. Mit der Krise des Jahres 1740 begann die Rivalität Österreichs mit Preußen, die zur Katastrophe von 1866 führen sollte, und man darf annehmen, daß die damaligen wesentlichen Veränderungen der Reichsverhältnisse die bedeutendste Konsequenz des Österreichischen Erbfolgekrieges darstellten.

Immerhin rettete Maria Theresia die Grundlagen der habsburgischen Macht, d. h. die Kaiserwürde und die Donaumonarchie. Der unerwartete Tod Kaiser Karls VII. im Januar 1745 und der Ausgleich mit seinem Nachfolger, Max III. Joseph, der im Vertrag von Füssen gegen die sofortige Evakuierung Bayerns auf alle Ansprüche Karl Albrechts verzichtete und sogar seine Kurstimme versprach ${ }^{62}$, erlaubte eine einstimmige Wahl Franz Stephans. Manche zeitgenössischen Historiker haben bewundert, wie zäh Maria Theresia gekämpft hatte, um die Kaiserwürde dem Haus Habsburg-Lothringen zu erhalten und den Mißerfolg der 1742er Kaiserwahl zu tilgen ${ }^{63}$. Es zeugt aber von wenig Verständnis für die damalige Reichsverfassung, weil Österreich nur dann eine Großmacht war, wenn sein Herrscher zugleich Reichsoberhaupt blieb, das eine führende Rolle auf dem Reichstag spielte. Auf diesem Gebiet war Feldmarschall Belle-Isle, der die Thesen der deutschen Verfassungsrechtler vertrat, besser informiert ${ }^{64}$ und viel scharfsinniger als Voltaire. Belle-Isle war davon überzeugt, daß, wenn Franz Stephan zum Kaiser gewählt würde, er die Reichsstände mobilisieren werde, um Lothringen zurückzuerobern ${ }^{65}$. Mit dem Dresdner Frieden (Dezember 1745) konnte das Haus Habsburg-Lothringen aber nicht seine ganze Territorialmacht retten, und Frankreich mußte endgültig seinen Traum aufgeben, eine vorrangige Stellung im Reich mit Hilfe der Vermittlung eines befreundeten Kaisers zu behaupten.

62 Alois Schmid, Max III. Joseph und die europäischen Mächte. Die Außenpolitik des Kurfürstentums Bayern 1745-1765 (München 1987).

${ }^{63}$ V.-L. Tapié versucht, Maria Theresia zu entschuldigen, weil sie um jeden Preis Franz Stephan zum Kaiser machen wollte, l'Europe de Marie Thérèse, S. 219.

${ }_{64}$ Man denke nur an die Menge ungedruckte Aufsätze, die noch heute im Pariser Archiv des Außenministeriums liegen, die vom Sekretär (Premier commis) Le Dran über die Rechte des Hauses Habsburg und die Reichsverfassung verfaßt wurden (Bestand Mémoires \& documents, Autriche). Sie sind allgemein Maria Theresia wenig günstig.

65 Belle-Isle, Ungedruckte Mémoires, Ms fr. 11.254, $\mathrm{f}^{\circ}$ 98-117. 
Im Jahre 1745 nahm der Krieg den Charakter eines langwierigen Konfliktes zwischen Frankreich und Großbritannien an; er wurde in den Niederlanden und in Italien (u. a. Belagerung von Genua) fortgesetzt - auch der Jakobitenaufstand in Schottland ist in diesem Kontext zu erwähnen -, und erst nach der Eroberung der Niederlande durch den französischen Feldmarschall Moritz von Sachsen brachte der Aachener Frieden ein vorläufiges Ende des europäischen Waffengangs. Obwohl Maria Theresia Mailand behielt und Franz Stephan der unbestrittene Herr des Großherzogtums Toskana blieb, mußte sie den Bourbonen noch die Herzogtümer Parma und Piacenza überlassen und zum dritten Mal den Verlust Schlesiens bestätigen. Der Aachener Frieden hat alle Teilnehmer enttäuscht, vor allem den siegreichen Ludwig XV., der seine Eroberungen auch zurückgab. Die französische öffentliche Meinung hatte den peinlichen Eindruck, daß man „für den König von Preußen“ sieben Jahre gekämpft und der Krieg, dessen Hauptzweck die endgültige Vernichtung des Hauses Habsburg-Lothringen war, nichts Positives gebracht hatte. Die damaligen Probleme Westeuropas hatten sich im Gegenteil verschärft, die Eroberungen in Übersee wurden im Austausch einfach zurückgegeben, die Auseinandersetzungen in Nordamerika hatten sich zugespitzt ${ }^{66}$. Spanien, dessen Eroberungen in Madrid als ungenügend bewertet wurden, war gegen Frankreich erbittert, so daß der Aachener Frieden in Paris wie in London eher als ein Waffenstillstand betrachtet wurde.

Das europäische Staatensystem, das aus den Ergebnissen des Rijswijcker Friedenskongresses entstanden war, wurde in Frage gestellt. Preußen erschien nun als ein neuer Stern, wenn auch seine Macht, die auf dem Heerwesen beruhte, leicht übertrieben wurde. Preußen gehörte von vornherein zum Klub der europäischen Großmächte mit Rußland, der Habsburger Monarchie, Frankreich und Großbritannien, der sogenannten Pentarchie. Spanien blieb eine Kolonialmacht, die dank der Nebenlinien der spanischen Bourbonen noch einen begrenzten Einfluß auf Italien ausübte. Die Habsburger waren keine Weltmacht mehr und herrschten vor allem über Mitteleuropa, wo sie jetzt in Wettbewerb mit Preußen traten. Die neue Großmacht, noch um 1700 fast unbekannt, war das russische Reich, das seinen dauerhaften Einfluß auf die polnische Adelsrepublik erweiterte und seit dem Frieden von Nystad (1721) scinen Vorrang im Ostseeraum behauptete, so daß keine Koalition ohne Teilnahme Rußlands gebildet werden konnte. In Westeuropa herrschte noch die Rivalität zwischen Frankreich und Großbritannien, die von 1715 bis 1740 durch den Willen beider Regierungen zwar zeitweilig entschärft wurde, dic aber auf widersprüchlichen Interessen in Übersee beruhte. Aus dieser Rivalität entstand eine kriegerische Stimmung in London und in Nordamerika. Frankreich brauchte unbedingt Verbündete auf dem Festland, um eine kostspiclige Kriegsmarine zu unterhalten, Verbündete, die es immer bei den Reichsständen und auch in Osteuropa gesucht hatte. Das Bündnissystem enthüllte während des Österreichischen Erbfolgekriegs seine Fehler. Kurbayern war sicher nicht mehr

${ }^{66}$ Jean Bérenger, Yves Durand, Jean Meyer, Pionniers \& Colons en Amérique du Nord, $\mathrm{XVI}^{\circ}$-XVIII ${ }^{\circ}$ siècles (Paris 1974 ). 
die leitende Macht im Reich, und Preußen war kein zuverlässiger Partner. Vor allem war Maria Theresia vom englischen Verbündeten besonders enttäuscht, weil er sie gezwungen hatte, Schlesien aufzugeben, so daß die große Allianz mit London, die 1689 nach der Glorreichen Revolution entstanden und 1701 in Den Haag bestätigt worden war, überhaupt keinen Sinn mehr für die Habsburger hatte ${ }^{67}$. Ludwig XV., der die von seinen Truppen besetzten Niederlande ohne Gegenleistung aufgab, hatte beim Aachener Frieden gezeigt, daß er keine Eroberungen wollte. Er war mit der Lösung der lothringischen Frage zufrieden, mit welcher man die Sicherung der französischen Ostgrenze endlich erreicht hatte. Maria Theresia war im Gegenteil über die britische Haltung von 1743 und 1745 erbittert. Sie war sich vollkommen bewußt, daß die englische Regierung ihr nie helfen würde, Schlesien zurückzuerobern. Deshalb dachte sie an eine Versöhnung mit den Bourbonen, die ihr Vater trotz des guten Willens Ludwigs XIV. (1715) und des Kardinals Fleury (1739) nic ernst genommen hatte. Das war ein schwieriges Unterfangen, weil eine Opposition in der Geheimen Konferenz entstand und weil die öffentliche Meinung in Frankreich habsburgfeindlich blieb. Der dauerhafte Ausgleich mit Frankreich war trotzdem der Hauptzweck der Botschaft von Kaunitz, der sich aus rationalen Gründen als ein leidenschaftlicher Anhänger des „renversement des alliances" erwies ${ }^{68}$.

Der Erbfolgekrieg hatte auch verhängnisvolle Konsequenzen für die Modernisierung der Habsburger Monarchie. Maria Theresia war sich der Schwäche der Verfassung und der Staatsfinanzen vollkommen bewußt, die ihr von ihrem Vater hinterlassen wurden. In der Barockzeit wurde keine Reform durchgesetzt, wir wissen heute, daß der österreichische Absolutismus nur eine Erfindung der späten Historiker ist ${ }^{69}$, daß die Pragmatische Sanktion nur eine dynastische Bindung zwischen den verschiedenen Kronländern brachte. Mit Unterstützung Franz I., der ein besserer Staatsmann als Feldherr war, versuchte Maria Theresia schon nach 1745, trotz des Widerstands des Hochadels, die meisten Fehlentwicklungen in der Regierung abzustellen. Das verräterische Verhalten der böhmischen Stände erlaubte es ihr, die selbständige Stellung Böhmens abzuschaffen und die allmächtige böhmische Hofkanzlei mit der österreichischen $1749 \mathrm{zu}$ vereinigen. Die Erfahrungen des Grafen Haugwitz, der zuerst in der Steiermark und nachher im österreichischen Schlesien als Landeshauptmann tätig war, boten die Grundlagen für eine Umwälzung der Ständeverwaltung. Dabei ist festzustellen, daß das Muster den Verwaltungsreformen König Friedrich Wilhelms I. entnommen wurde. Die Unabhängigkeit der Ständeverwaltung wurde abgeschafft, und die Steuereinnehmer wurden zum ersten Mal seit 1526 königliche Beamte. Wenn die Landtage, die aus Hochadeligen und Prälaten bestanden, die Steuerbewilligung behielten, so mußten sie eine Pauschalkontribution bewilligen, die zum Unterhalt eines auf

${ }^{67}$ Siehe auch Max Braubach, Versailles und Wien von Ludwig XIV. bis Kaunitz. Die Vorstadien der diplomatischen Revolution im 18. Jahrhundert, 2 Bde. (Bonn 1952).

${ }^{68}$ Franz A. J. Szabo, Kaunitz and Enlightened Absolutism 1753-1780 (Cambridge 1994).

69 Bérenger, Finances \& Absolutisme autrichien dans la seconde moitié du XVIIème siècle, Conclusions, $450-470$. 
dem Friedensfuß von 120.000 Mann starken Heeres gebraucht wurde, das der Wiener Hofkriegsrat als notwendig betrachtete, um die Monarchie zu verteidigen und einen neuen Einfall Friedrichs II. verhindern zu können. Dieser Betrag bildete eine Minimalkontribution, die bei jeder Sitzung der verschiedenen Landtage nicht mehr zu diskutieren war, auf denen aber andere Steuern Gegenstand leidenschaftlicher Debatten blieben. Durch die sogenannte Reform von Haugwitz wurde den Landständen ihr Steuerbewilligungsrecht nicht genommen, sondern nur im Interesse des Staates begrenzt. Übrigens galt diese positive Reform nur für den Kern der Monarchie (die deutschen Erblande und die Länder der Krone Böhmens), weil die Niederlande, Mailand und vor allem das Königreich Ungarn ihre finanziellen Vorrechte retteten. Wenn Mailand viel zum Aufkommen der Staatskasse beitrug, blieb Ungarn wie üblich fast steuerfrei. Aus dieser Reform resultierte indessen die österreichische Staatsverwaltung mit kaiserlichen Beamten. Aber ohne den Anstoß des Erbfolgekriegs hätte kein Wiener Herrscher den Widerstand des Hochadels beugen können, der sich als Mitregent der Monarchie in der Barockzeit behauptete. Mit dieser ersten Verwaltungsreform setzte eigentlich die Ära der Aufklärung ein, die die Regierungszeit Maria Theresias charakterisiert.

Drei Erbfolgekriege haben dic Natur der Habsburger Monarchie beträchtlich verändert. Maria Theresia verfolgte ganz andere Ziele als ihr Großvater, der gewissermaßen noch in den Kategorien Karls V. dachte: Die Erzhauspolitik war immer ein wichtiger Bestandteil seiner Diplomatie, und wenn eine zeitweilige Schwäche der Donaumonarchie ihn an eine Teilung seiner Erbschaft denken ließ, so strebte er nach dem Sieg gegen die Türken und mit der Unterstützung der Seemächte danach, sich des ganzen Habsburgerreiches zu bemächtigen, was auf keiner anderen Basis als auf legitimen Patrimonialrechten und der Treue der Untertanen beruhte. Mit Maria Theresia, die sich als eine der klügsten Regentinnen unter den Staatsmännern des frühneuzeitlichen Europas behauptete, wird die Umwandlung der Habsburger Monarchie deutlich: Anstatt nach einem Universalreich zu streben, ist sie eine von Grund auf mitteleuropäische Großmacht, deren Kräfte im Donauraum, in Norditalien und in Deutschland liegen. Um die negativen Konsequenzen der Erbfolgekrise zu beseitigen, begann Maria Theresia, die Monarchie nach preußischem Muster zu erneuern und das Allianzsystem grundlegend zu verändern, weil sie hoffte, auf diese Weise Schlesien zurückerobern, ihre Vormachtstellung im Reich wiederherstellen und die Donaumonarchie als europäische Großmacht noch besser behaupten zu können. Abschließend bleibt festzuhalten, daß die drei Erbfolgekriege, die wir kurz analysiert haben, unbestreitbar wichtige Faktoren der Entwicklung der österreichischen Monarchie, des Reiches sowie des europäischen Staatensystems im 18. Jahrhundert waren. 